\title{
Grand challenges in atmospheric science
}

\author{
Luis Gimeno* \\ EPhysLab, Facultade de Ciencias, Universidade de Vigo, Ourense, Spain \\ *Correspondence: I.gimeno@uvigo.es \\ Edited by: \\ Martin Beniston, University of Geneva, Switzerland
}

Keywords: atmospheric science grand challenges, atmospheric dynamics, atmospheric physics, physics of climate, atmospheric chemistry

As a subject of study, the atmospheric sciences encompass all the processes that occur in the atmosphere, together with its links with other systems, mainly the hydrosphere, cryosphere, lithosphere, biosphere, and outer space. As such it is an extensive discipline and the task of describing the main challenges is not an easy one, and entails a fair degree of overlap with some of the other grand challenges in the earth and environmental sciences. As a special overlapping could occur with climate sciences it is worth to remember that atmospheric processes differ from climate ones in the temporal scale, being the latter those occurring over long periods, typically higher than 30 years, but in any case long enough to produce meaningful averages. Atmospheric processes are central to configure the state of the climate but also to many of the forcings and feedbacks that determine the magnitude of climate change and its possible impacts. Additionally, there has been impressive progress of late in the atmospheric sciences in terms of the benefits provided to individuals and organizations. The flow of atmospheric "information" is of considerable importance in decisions related to health, agriculture, energy, power, and the environment. This "Grand Challenges" article focuses on the atmosphere, although the strong interaction with other parts of the earth and its environment, together with the societal implications involved, is a common theme in all the challenges described.

Over the next few years, progress in the atmospheric sciences is essential if understanding of the basic processes and their modeling is to improve; this will require genuine advances in observational, conceptual, and technological approaches. For this reason the following non-exhaustive list of 12 selected challenges includes those related to observations and data assimilation, those covered within the traditional disciplines (atmospheric physics and chemistry, atmospheric dynamics and weather forecasting), those concerned with the interactions between the atmosphere and its boundaries, and those related to the atmospheric component of climate studies.

\section{CHALLENGE 1: DATA ASSIMILATION}

The challenges in terms of data assimilation for earth observation over the next years relate to technical and general thematic aspects, as well as to the ability to take advantage of new and exciting opportunities in earth observation systems. The benefits of addressing these challenges are likely to include improvements to reanalyses, improvements to weather forecasting, an improved observational system, and an improved foundation on which the elements of climate models can be built. Among the technical challenges, five areas are most significant: (1) the assimilation of coupled data to account for links between different elements of the earth's system; examples include the coupling of the atmosphere and the ocean, of the ocean and the cryosphere, and of the atmosphere and the land; (2) assimilation of ensemble data to account for natural variability and/or to represent errors in the earth system-here, the technical effort will focus on the design of realistic ensembles; (3) performing data assimilation at increased spatial resolutions, representing the earth system at finer scales (mesoscale and finer), including theoretical developments to account for changes in balance conditions; (4) better representation of errors (random and bias) in the observations and models used in data assimilation, including the representation of forecast errors, model errors and online bias correction; (5) extension and consolidation of the joint state estimation and the inverse modeling approach in order to study biogeochemical cycles (e.g., the carbon cycle). The overarching challenge here is the consolidation and integration of the community data assimilation efforts of the meteorological and space agencies, of research and operational activities, and from in situ and satellite observational platforms, including all continental and global collaborations, and the effective application of these efforts toward the development of new missions in earth observation.

\section{CHALLENGE 2: SMALL SCALE PROCESSES IN THE ATMOSPHERE}

Several challenges are apparent in terms of our fundamental understanding of small scale processes and related applications, many of which are in currently being actively debated and studied. First, increased computational power allows the more detailed simulation of fluid mechanics problems, thus, even stably stratified flows are now modeled by direct numerical simulation. At the same time, these advanced computational techniques also require a new generation of parameterization schemes for numerical weather prediction (NWP) and climate modeling. At high resolutions, for example, the complex dynamics that occur in urban areas cannot be neglected and specific NWP schemes to represent these are required. At smaller grid sizes the so-called gray zone of turbulence is approached in NWP, and the impact of this must be understood and quantified. There is some room for improvement in terms of the representation of clouds and of the diurnal cycle of deep convection, and the same also applies to the physical processes that govern the stable boundary layers and the 
diurnal cycle, and the intermittent nature of turbulence, especially under calm conditions. In addition, higher resolutions also require more advanced techniques to allow the interpretation of the observations made. In boundary-layer meteorology, the closure of the surface energy balance and the heat budget in field observations requires further attention. Finally, the data challenges facing meteorology will also increase, due in particular to the greater availability of both professional and crowd-sourced observations (Muller et al., 2013).

\section{CHALLENGE 3: AIR POLLUTION CHEMISTRY}

The key components of a program to address the most important challenges for researchers in air pollution chemistry may be described under the following three headings: (1) Indoor Pollution and health: given the tendency for people to remain largely indoors for work, school, and leisure, it is important to study the impact of indoor pollution on human health as a result of indoor emissions and/or the infiltration of the external ambient air. In recent years the processes that govern indoor air quality have changed markedly as result of modifications to building regulations with the aim of better energy efficiency. There are still considerable unknowns in relation to the sources, compounds and processes that affect indoor air quality and its impact on human wellbeing. (2) Dust and air quality: with continuous improvements in the characteristics of vehicle emissions, the effects of aerosol pollution in urban areas can now increasingly be traced to other sources of emissions, such as the transport of natural dust and the resuspension of road dust, mainly in southern European areas with drier climates in areas affected by the transport of dust from the deserts of North Africa. An understanding of these impacts and the application of mitigation measures (for road dust resuspension) are both areas of future research. (3) Biomass burning: with climate change and concerns about the impact and cost of fossil fuels, biomass combustion is now commonly used for domestic heating in Europe. In many urban areas, principally in winter, domestic biomass has been found to be an important source of air pollution by particulates. Ar present some emphasis is being placed on the evaluation of the impact of biomass burning in terms of urban air quality as well as in terms of the study of the emission characteristics of biomass burning equipment and installations, as well as on the impact of the composition of biomass burned particles on human health.

\section{CHALLENGE 4: AEROSOL-CLOUD INTERACTIONS}

There is no doubt that aerosol particles are actively involved in cloud formation via the supply of cloud condensation nuclei (CCN) and ice nuclei (IN). It has been suggested that changes in aerosol concentrations will alter cloud lifetimes and precipitation efficiency, and hence affect the radiative forcing of the earth system. Great efforts have been devoted to this topic, resulting in rapid developments in terms of knowledge, methodologies, and techniques (e.g., Wang, 2013). Despite this progress, it is still difficult to draw any meaningful conclusions about the climatological effects of aerosols at regional and global scales. In contrast, aerosol-cloud interactions at molecular and microphysical scales have become more and more predictable and its modeling more deterministic. There appears to be a significant gap in our knowledge between the smallscale (molecular and microphysical) processes and the large-scale (regional/global) events in this area. We suggest that there remains a need to synthesize multi-scale results to identify clearly the problems involved and to improve the current set of tools and methodologies required to close the gap.

\section{CHALLENGE 5: WEATHER PREDICTION}

Phenomena described by fluids are complex, however, the appearance of the laws of fluid motion is deceitfully simple, equations governing these laws are non-linear, what implies multiple (and hard to understand) types of feedback effects. The atmosphere and the temporal evolution of its state does not deliver from this problem. In any case one of the flagships of the body of research on atmospheric sciences over the last few decades has been the establishment of reliable forecasting in the 2-7-day range, in view of the enormous potential economic benefits; however, such techniques still suffer from problems derived from the collection and utilization of data, which are mostly collected over the oceans. The use of new data from satellites and groundbased remote sensing could help in this regard, as could the correct maintenance of traditional data sets such as the now some what outdated global rawinsonde network. Improvements in measurements of water vapour and land surface properties are also priorities. The physical challenges continue to be the same as they were when defined more than a decade ago (National Research Council, 1998), namely: a better understanding of the nature of the interaction between atmospheric and land surface processes, the hydrological cycle, the dynamics of deep convection, the role of the tropopause in atmospheric dynamics, a fresh impetus in the development of mesoscale models and an improvement in the parameterizations used in the wave-based models of weather and climate. An example of the importance of these improvements is orographic gravity wave drag, whose parameterization in weather and climate prediction models needs to be updated given the importance of some effects shown to be important in recent research. Among these is the impact of wind shear on both the surface drag and the wave momentum flux (and its dissipation), and the drag produced by trapped lee waves, whose energy propagates, and is dissipated, downstream of their source rather than upwards. The implications of these orographic gravity waves for clear-airturbulence (CAT), a very serious aviation hazard, have not been satisfactorily quantified. Most CAT forecast methods use empirical predictors not explicitly linked to gravity waves, but it is well known that directional shear (which is ubiquitous in nature) leads to gravity wave breaking, which may be an important source of CAT. The trapping of gravity waves in the lee of mountains or hills leads to the formation of unsteady, turbulent, closed circulations known as rotors, which are also a serious aviation hazard. Our understanding of the conditions necessary for the onset of these flow structures is incomplete, and will no doubt benefit from recent advances in mountain wave theory. 


\section{CHALLENGE 6: REMOTE SENSING FOR} METEOROLOGY AND CLIMATE

Ground-based and satellite remote sensing has provided major advances in our understanding of both the weather and the climate systems, as well as the changes in these (Yang et al., 2013), by allowing the quantification of the processes and spatiotemporal states of the atmosphere, land, and oceans. The intensive use of satellite imagery in meteorology, and spatial patterns of sea level rise, provide good examples of this. The duration of the time series concerned are usually too short to allow their use for capturing long term trends of many climate variables, so one major challenge is to extend the durations of these time series. Remote sensing of the regional and global cycles of clouds and precipitation is also necessary for climate monitoring and the verification of model outputs. There are two notable challenges in atmospheric physics; the first is to design innovative studies focusing on cloud microphysics and the relationship with the physics of lightning discharge, together with all aspects related to the observation and measurement of atmospheric electricity, and the second is to develop new passive radiometer and radar studies to help us to understand the structure of clouds and precipitation with special emphasis on tropical warm rain processes, mid-latitude light precipitation, snowfall, cloud liquid and ice water content, precipitable water and water vapour profiles. One hydrometeorological challenge is to extend and improve our observations and modeling of the atmospheric and continental parts of the water cycle in order to allow its closure (e.g., mountain areas, polar regions).

\section{CHALLENGE 7: THE ATMOSPHERIC BRANCH OF THE HYDROLOGICAL CYCLE}

Among the many challenges related to the hydrological cycle, those concerned with the atmospheric transport of moisture must receive special mention because of their existence entirely within the realm of the atmospheric sciences. Here we consider the most pressing of the challenges described in the recent review of Gimeno et al. (2012). The diagnosis of moisture sources has become a major research tool in the analysis of extreme events (e.g., floods, droughts), and can be thought of as a basic tool for regional and global climatic assessments; it is therefore, necessary to check the consistency of the different approaches used to establish source-sink relationships for atmospheric water vapour. Of key importance is the improvement of our understanding of how sources of moisture affect precipitation isotopes; this is important in and of itself but it is also crucial for correctly interpreting the most prominent paleoclimatic archives including ice cores and cave sediments. A further challenge is the better understanding of the role of the transport of moisture as the main factor responsible for meteorological extremes (heavy rainfall via structures such as low level jets and atmospheric rivers, or drought via the prolonged diminished supply of water vapor from moisture source regions). In order to assess whether the moisture source regions have remained stationary in past years, it is necessary to understand the effects of the main modes of climate variability on the variability of the moisture regions, and how the transport of moisture occurs in a changing climate. These unsolved questions constitute a substantial challenge for climate scientists.

\section{CHALLENGE 8: INTERACTION OF SCALES IN CLIMATE SIMULATION}

The interaction among various spatial and temporal scales results in what we call climate. Lorenz (1967) was among the first to emphasize the importance of scale interactions in explaining some of the key characteristics of climate observed in various regions. The non-linear character of most of these scale interactions has made them difficult to model, and as a consequence this still constitutes a source of uncertainty in climate simulations. Some empirical methods have been proposed to downscale the output from climate models but these are still somewhat controversial (Pielke and Wilby, 2011), particularly when used to interpret long term climate projections at a regional scale. The use of boundary conditions from an global model in which coupled interactions among all the major subsystems of the climate system (atmosphere, ocean, biosphere, and cryosphere) are predicted has a number of problems as the retention of large-scale climate errors in the global models, its great dependence on the lateral boundary conditions or the lack of two-way interaction between the regional and global models. The role of small scale atmospheric processes, usually in short lived phenomena, turns to be highly relevant particularly in tropical regions, where mesoscale convective systems interact with large scale circulations, and are of crucial importance in the hydrological cycle. For example, tropical cyclones may result in very wet or dry years in some regions depending on their activity and trajectory. This element is rather difficult to simulate in climate models, but its contribution to regional climate is beyond doubt and must be better understood in order to incorporate it into climate modeling systems.

\section{CHALLENGE 9: EXTREME EVENTS}

In recent years the effects of different meteorological and climate phenomena have gained in importance in the eyes of the media and the population as a whole, partly as a consequence of extreme events such as the heatwaves in Europe (2003), Russia (2010), or USA (2011), or the deadly and extremely costly hurricanes that have hit densely populated areas in recent years, including New Orleans (Katrina, 2005) and the Metropolitan area of New York (Sandy, 2012). Likewise, prolonged periods of drought have caused severe problems for cereal producers, including in southern Australia (2002-2010), or the south-western USA, or via the increased likelihood of forest fires (Amazonia, 2005 and 2010). Some of these extreme events are closely related to the occurrence of vigorous circulation patterns such as the North Atlantic Oscillation (NAO), or to blocking and the displacement of storm tracks and the jet stream. By definition, extremes are rare in a time series, there is therefore, a pressing need, linked to the analysis of extreme events, to extend the climatic series as far as possible, and for this reason reconstructions of the past climate based on instrumental, historical and proxy data continue to be indispensable. The recent IPCC report (IPCC, 2013) shows that this growing interest in climatic extreme events must be addressed within the wider context of climate change, given that the expected changes in global, regional and even local climates are most 
likely to be felt through changes in the magnitude and frequency of extreme events.

\section{CHALLENGE 10: SOLAR INFLUENCE ON CLIMATE}

It has been estimated that about $8 \%$ of recent global climate change can be attributed to solar variability, but this figure must be treated with caution given that a number of aspects of solar forcing and the mechanisms coupling solar variability to the earth's climate system remain poorly understood (Gray et al., 2010). With the increasing complexity and sophistication of atmospheric and climate models, and the need for increased accuracy of the predictions made, it is important to able to include a more complete picture of solar forcing in these models. Sources of solar forcing can be divided into radiatively and particle driven components. The scientific focus for the radiatively driven forcing is currently shifting from the global to the regional responses as driven by variations in solar spectral irradiance (SSI). A number of questions remain about the nature of the variations in SSI, how these should be implemented in models, and how they will change in future solar cycles if the sun moves away from its current grand maximum of solar activity toward a new maunder minimum. The particle driven component is further divided into energetic particle precipitation (EPP) and cosmic ray (CR) effects. The EPP effect initially influences the upper stratosphere and lower thermosphere. While the chemical effects of EPP on the atmosphere are now well understood, there is a pressing need to understand further dynamical effects, as well as the potential mechanisms and magnitudes in terms of the earth's climate. The potential influence of EPP on climate is an emerging research area, and is one that is assuming a greater importance now that climate models are extending to higher altitudes that are more directly influenced by EPP. EPP provides one of the key transport pathways from the lower thermosphere down to the stratosphere and beyond, down to the troposphere via stratosphere-troposphere coupling in the polar regions. The effect of EPP could also become more pronounced in the near future as radiative forcing becomes more influenced by a move to maunder minimum types of solar activity. The CR driven component is currently considered to be the least well understood of the sources of solar forcing, although dedicated ongoing international research efforts are being made to address this question. Resent results have suggested that although CRs may stimulate aerosol nucleation, in global terms these effects are not great, and questions remain on the physical mechanisms linking CRs and aerosol nucleation.

\section{CHALLENGE 11: URBAN WEATHER AND CLIMATE}

The urban heat island (UHI) is perhaps the best known effect of the presence of cities on the local microclimate; the air temperature in a city at night can be much higher (up to $10^{\circ} \mathrm{C}$ or more) than in the surrounding area. Urban Climate, an emerging branch of meteorology 20 years ago, is now a mature field of research. It covers a range of topics, from fundamental theoretical studies to more applied research, having as its main goal the application of climatic knowledge to the better design of cities around the world. Micrometeorology has always been a core area of interest in urban studies because of the scales involved. Urban climatology instrumentalists have pioneered the continuous development of instrumentation and process analysis ever since the 1970s. The processes leading to the formation of the UHI (mostly physical in nature due to the 3D shape and the materials that make up the urban fabric), emerged from these early studies. Today, a number of challenges remain in relation to the measurement of this rather complex urban boundary layer. New short-range teledetection instruments are being used to gain a specialist view of the physical processes involved. Such instrumental developments will inevitably continue. Urban climate was only tackled by atmospheric modellers when the atmospheric models reached a sufficiently high resolution (a few $\mathrm{km}$ ) to be able to represent cities explicitly. The first models representing the exchanges of energy and water between urban surfaces and the atmosphere appeared in the early 2000s (see reviews in Masson, 2006 and Martilli, 2007), and are now being used more and more in numerical weather forecasting models. The first international intercomparisons of urban models (Grimmond et al., 2010, 2011) discussed some obvious means of improvement, for example in the representation of urban vegetation. In addition, approximately 15 years later than atmospheric models, regional climate models now have spatial resolutions compatible with urban scales. This of course presents a new challenge in the proper representation of cities in climate models. Similarly, urban meteorology studies cannot be limited to physics or chemistry, but must take account of the behavior of the inhabitants. Although biometeorological studies already exist, especially in terms of levels of human comfort, the interactions between the meteorological and social worlds, both in terms of human comfort but also in terms of meteorologically dependant energy use, for example, still form one of the main challenges for urban meteorologists.

\section{CHALLENGE 12: OZONE DEPLETION AND RECOVERY}

Although stratospheric ozone concentration minima are still seen in many regions, signs of recovery are beginning to be perceived. In the Antarctic stratosphere the concentration of halocarbons peaked around the year 2000 and then began to diminish. Current projections suggest that complete recovery could occur around the year 2050. This means that one of the major challenges is to ensure the continued monitoring both of ozone and of ozone-depleting gases in order to guarantee the recovery. Improvements in the basic understanding of processes, and simulations thereof, are especially important in the context of a changing climate. Both directions must be simulated, i.e., how a changing climate will affect the ozone layer, and how the recovery of the ozone will affect weather and climate. The so-called climate-chemistry models (CCMs, Lamarque et al., 2013) appear to be of key importance in this case.

The foregoing list of challenges for the next few years in atmospheric sciences research relates only to a few of the most urgent unsolved questions and naturally remains incomplete. The challenges described herein must not be considered 
to be the likely principal research topics in Frontiers in Atmospheric Science; any interesting work linked to the umbrella of atmospheric science should find accommodation in the journal.

\section{ACKNOWLEDGMENTS}

Supported in part by MINECO (Spain), project TRAMO and FEDER. The team of Associated Editors of Frontiers in Atmospheric Science provides useful comments.

\section{REFERENCES}

Gimeno, L., Stohl, A., Trigo, R. M., Dominguez, F., Yoshimura, K., Yu, L., et al. (2012). Oceanic and terrestrial sources of continental precipitation. Rev. Geophys. 50:RG4003. doi: 10.1029/ 2012RG000389

Gray, L. J., Beer, J., Geller, M., Haigh, J. D., Lockwood, M., Matthes, K., et al. (2010). Solar influences on climate. Rev. Geophys. 48:RG4001. doi: 10.1029/2009RG000282

Grimmond, C. S. B., Blackett, M., Best, M. J., Barlow, J., Baik, J-J., Belcher, S. E., et al. (2010). The international urban energy balance models comparison project: first results from phase 1. J. Appl.
Meteorol. Climatol. 49, 1268-1292. doi: 10.1175/ 2010JAMC2354.1

Grimmond, C. S. B., Blackett, M., Best, M. J., Barlow, J., Baik, J-J., Belcher, S. E., et al. (2011). Initial results from Phase 2 of the international urban energy balance model comparison. Int. J. Climatol. 31, 244-272. doi: 10.1002/joc.2227

IPCC. (2013). Climate Change: The Assessment Report of the Intergovernmental Panel on Climate Change. Cambridge, UK: Cambridge University Press.

Lamarque, J.-F., Shindell, D. T., Josse, B., Young, P. J., Cionni, I., Eyring, V., et al. (2013). The atmospheric chemistry and climate model intercomparison project (ACCMIP): overview and description of models, simulations and climate diagnostics. Geosci. Model. Dev. 6, 179-206. doi: 10.5194/gmd6-179-2013

Lorenz, E. N. (1967). The Nature and Theory of the Atmosphere. Geneva: WMO, 161.

Martilli, A. (2007). Current research and future challenges in urban mesoscale modelling. Int. J. Climatol. 27, 1909-1918. doi: 10.1002/joc.1620

Masson, V. (2006). Urban surface modeling and the meso-scale impact of cities. Theor. Appl. Climatol. 84, 35-45. doi: 10.1007/s00704-0050142-3

Muller, C. L., Chapman, L., Grimmond, C. S. B., Young, D. T., and Cai, X. (2013). Sensors and the city: a review of urban meteorological networks. Int. J. Climatol. 33, 1585-1600. doi: $10.1002 /$ joc. 3678
National Research Council. (1998). The Atmospheric Sciences: Entering the Twenty-First Century. Washington, DC: The National Academies Press.

Pielke, R. A. Sr., and Wilby, R. L. (2011). Regional climate downscaling - what's the point? EOS 93, 52-53. doi: 10.1029/2012EO050008

Wang, C. (2013). Impact of anthropogenic absorbing aerosols on clouds and precipitation: a review of recent progresses. Atmos. Res. 122, 237-249. doi: 10.1016/j.atmosres.2012.11.005

Yang, J., Gong, P., Fu, R., Zhang, M., Chen, J., Liang, S., et al. (2013). The role of satellite remote sensing in climate change studies. Nat. Clim. Change 3, 875-883. doi: 10.1038/nclimate1908

Received: 10 October 2013; accepted: 17 October 2013; published online: 29 October 2013.

Citation: Gimeno L (2013) Grand challenges in atmospheric science. Front. Earth Sci. 1:1. doi: 10.3389/feart. 2013.00001

This article was submitted to Atmospheric Science, a section of the journal Frontiers in Earth Science.

Copyright (c) 2013 Gimeno. This is an open-access article distributed under the terms of the Creative Commons Attribution License (CC BY). The use, distribution or reproduction in other forums is permitted, provided the original author(s) or licensor are credited and that the original publication in this journal is cited, in accordance with accepted academic practice. No use, distribution or reproduction is permitted which does not comply with these terms. 